\title{
Factors in health initiative success: Learning from Nepal's newborn survival initiative
}

\author{
Stephanie Smith ${ }^{33}$ \\ University of New Mexico
}

What determines the success of health initiatives in acquiring sufficient levels of political priority to alleviate significant health problems in low-income countries? We investigate this question in the context of significantly increasing political priority for newborn survival in Nepal since the turn of the century. We use a process-tracing methodology to investigate the causes of this shift, drawing on twentynine interviews with individuals close to newborn health policymaking in Nepal and extensive document analysis. Shifts in the political context (commitments to the child health MDG), the strength of concerned actors (emergence of collective action, leadership, resources) and the power of ideas (problem status, existence of contextually relevant solutions, agreement on these points) surrounding the issue have been instrumental in elevating priority for newborn survival, if not institutionalizing that priority to ensure long-term support. The findings highlight the significance of political fragmentation in war-torn areas for impeding priority generation and impact. They also suggest that theories of social construction provide important insights to the sources and roles of ideas in shaping health initiative success.

\footnotetext{
${ }^{33}$ Assistant Professor of Public Administration, University of New Mexico. Email: smith.unm.spa@gmail.com.
} 